\title{
PENDETEKSIAN KECURANGAN LAPORAN KEUANGAN DENGAN ANALISIS FRAUD TRIANGLE PADA PERUSAHAAN PERBANKAN YANG TERDAFTAR DI BURSA EFEK INDONESIA
}

\author{
Abdul Rahman ${ }^{1}$ \\ Akuntansi Keuangan Publik \\ Politeknik Negeri Medan \\ abdulrahmandalimunthe@ polmed.ac.id
}

\author{
Deliana Deliana ${ }^{2}$ \\ Akuntansi Keuangan Publik \\ Politeknik Negeri Medan \\ deliana@polmed.ac.id
}

\author{
Daniel Gopas ${ }^{3}$ \\ Akuntansi Keuangan Publik \\ Politeknik Negeri Medan \\ danielgopas@gmail.com
}

\begin{abstract}
This study aims to prove the risk factors that lead to fraudulent financial statements consisting of financial stability, external pressure, personal financial needs, financial targets, the nature of the industry, ineffective supervision and changes in KAP. The research was conducted at banking companies listed on the Indonesian stock exchange. The hypothesis testing using multiple regression analysis. The results of this study indicate that the Financial Target (ROA) \& Nature Of Industry (RPT) led to partial Financial Statement Fraud in banking companies listed on the Indonesian Stock Exchange for the period 2016-2019. Financial Stability (ACHANGE), Personal Financial Need (OSHIP), External Pressure (LEV), Effective Monitoring (BDOUT) \& Rationalization (AUDCHANGE) do not cause partial financial statement fraud.
\end{abstract}

Keywords: Risk, Financial Statement Fraud, Pressure, Opportunity, Rationalization.

\begin{abstract}
Abstrak
Penelitian ini bertujuan untuk membuktikan faktor risiko yang menyebabkan kecurangan laporan keuangan yang terdiri dari stabilitas keuangan, tekanan eksternal, kebutuhan keuangan pribadi, target keuangan, sifat industry, pengawasan yang tidak efektif dan perubahan KAP. Penelitian dilakukan pada perusahaan Perbankan yang terdaftar di bursa efek Indonesia. Uji hipotesis menggunakan analisis regresi berganda. Hasil penelitian ini menunjukan bahwa Financial Target (ROA )\& Nature Of Industry (RPT) menyebabkan kecurangan laporan Keuangan (Financial Statement Fraud) secara parsial pada perusahaan perbankan terdaftar di Bursa Efek Indonesia periode tahun 2016-2019. Financial Stability (ACHANGE), Personal Financial Need (OSHIP), External Pressure (LEV), Ineffetive Monitoring (BDOUT) \& Rationalization
\end{abstract}


(AUDCHANGE) tidak menyebabkan kecurangan laporan keuangan (financial Statement Fraud) secara parsial.

\section{Kata Kunci: Risiko, Kecurangan Laporan Keuangan, Tekanan, Peluang, Rasionalisasi.}

\section{PENDAHULUAN}

Kecurangan merupakan salah satu perilaku yang menjadi masalah di setiap negara, baik di negara berkembang ataupun di negara maju. Kecurangan adalah tindakan yang dilakukan perseorangan ataupun terorganisir dalam satu kelompok dengan tujuan utama yaitu untuk mendapatkan keuntungan dari berbagai aspek dengan berbagai tindakan diantaranya penipuan, penyalahgunaan wewenang, ataupun tindakan yang dapat merugikan berbagai pihak termasuk individu maupun entitas perusahaan lainnya. Salah satu kecurangan yang sering terjadi adalah kecurangan pada laporan keuangan.

Informasi yang digunakan dari laporan keuangan ditujukan kepada pihak-pihak yang terkait, baik di dalam perusahaan maupun di luar perusahaan sebagai alat pertanggungjawaban dan untuk menarik investor baru. Perusahaan selalu ingin menunjukkan kinerja keuangan yang baik agar pihak investor tertarik untuk berinvestasi di perusahaannya, dan ini menjadi salah satu penyebab perusahaan melakukan kecurangan laporan keuangan.

Tindakan kecurangan pada laporan keuangan menyebabkan informasi yang terkandung dalam laporan keuangan menjadi tidak relevan dan menyebabkan salah saji material sehingga menyesatkan pengguna laporan keuangan (Susianti, 2015). Peningkatan jumlah kecurangan laporan keuangan dan kegagalan bisnis menyebabkan kekhawatiran tentang legitimasi laporan keuangan perusahaan (Lou dan Wang, 2009).

Kecurangan laporan keuangan terjadi di PT Tiga Pilar Sejahtera Tbk (AISA) pada tahun 2021, rekayasa fundamental perusahaan dilakukan dengan cara melambungkan harga saham perseroan, sehingga membuat para investor banyak melakukan investasi, namun pada kenyataannya hal tersebut hanya rekayasa yang dibuat oleh direksi. Pada akhirnya PT Tiga Pilar Sejahtera Tbk terungkap telah melakukan manipulasi dan perusahaan tersebut gagal membayar bunga obligasi dan suku ijarah (bisnis.com). Kecurangan laporan keuangan juga terjadi di salah satu perusahaan perbankan di Indonesia dengan memberikan kredit uang tidak sesuai 
peruntukannya, hal ini di duga perusahaan melakukan window dressing, yang merupakan suatu strategi perusahaan untuk menarik hati investor dengan cara mempercantik laporan keuangan dan portofolio bisnisnya (klikanggaran.com).

Risiko kecurangan dapat terjadi karena adanya tekanan, peluang dan rasionalisasi. Tekanan bagi manajemen akan timbul pada kondisi perusahaan yang tidak stabil hal ini disebabkan penurunan kepercayaan publik atas kinerja perusahaan, sehingga mengganggu investasi tahun mendatang (Ratmono, 2017). Pada saat stabilitas dan kondisi ekonomi perusahaan terancam, harapan pihak ketiga yang harus dipenuhi, kebutuhan keuangan manajer dan target yang harus dicapai mengakibatkan kecurangan laporan keuangan dilakukan oleh manajer (Yesiariani, 2017). Selain karena adanya tekanan, kecurangan laporan keuangan juga dapat disebabkan karena adanya peluang atau kesempatan, kecurangan laporan keuangan dapat disebabkan oleh sifat industri dan kurangnya pengawasan. Rasionalisasi juga dapat menjadi salah satu penyebab kecurangan laporan keuangan. Rasionalisasi adalah adanya sikap atau nilai etis yang merupakan pembenaran dari seseorang, sehingga dia merasa tidak bersalah pada saat melakukan kecurangan (Amaliah, 2015). Masalah penelitian ini adalah apakah stabilitas keuangan, tekanan eksternal, kebutuhan keuangan pribadi, target keuangan, sifat industri pengawasan yang efektif dan rasionalisasi berpengaruh terhadap kecurangan laporan keuangan, dan tujuan penelitian ini adalah untuk membuktikan secara empiris faktor risiko yang menyebabkan kecurangan laporan keuangan yang terdiri dari stabilitas keuangan, tekanan eksternal, kebutuhan keuangan pribadi, target keuangan, sifat industri, pengawasan yang efektif, dan rasionalisasi.

\section{KERANGKA PEMIKIRAN DAN PENGEMBANGAN HIPOTESIS}

\subsection{Stabilitas Keuangan Menyebabkan Kecurangan Laporan Keuangan}

Manajer menerima tekanan untuk melakukan perbuatan financial statement fraud ketika stabilitas keuangan (financial stability) terancam oleh keadaan ekonomi, industri, dan situasi entitas yang beroperasi (AICPA 2002). Manajemen seringkali mendapatkan tekanan dari pihak investor karena mengharapkan laba yang tinggi agar menghasilkan return yang tinggi. Laporan keuangan digunakan manajemen untuk menutupi kondisi keuangan yang sebenarnya. Penelitian Skousen et al. (2009) menunjukkan bahwa perubahan total aset mempengaruhi financial statement fraud. 


\section{H1. Stabilitas Keuangan menyebabkan Kecurangan Laporan Keuangan}

\subsection{Kebutuhan Keuangan Pribadi Menyebabkan Kecurangan Laporan Keuangan}

Personal financial need merupakan suatu kondisi eksekutif perusahaan dapat mempengaruhi keuangan perusahaan. Manajemen memiliki wewenang yang tinggi dalam pengambilan keputusan diperusahaan. Saham yang dimiliki oleh pihak internal perusahaan akan mempengaruhi kondisi keuangan perusahaan. Pelaku kecurangan akan memanipulasi laporan keuangan jika kondisi presentase kepemilikan saham semakin tinggi. Penelitian Skousen et al. (2009) menunjukkan bahwa persentase kepemilikan saham oleh orang dalam (OSHIP) menyebabkan kecurangan laporan keuangan.

H2. Kebutuhan Keuangan Pribadi menyebabkan Kecurangan Laporan Keuangan

\subsection{Tekanan Pihak Luar Menyebabkan Kecurangan Laporan Keuangan}

Tekanan pihak luar (external pressure) adalah tekanan yang diberikan pihak ketiga demi memenuhi harapan dan persyaratan pihak ketiga. Manajemen selalu tertekan pada kondisi saat perusahaan membutuhkan tambahan dana dan harus melakukan pinjaman yang kompetitif dari pihak luar (Skousen, 2009).

H3. Tekanan pihak luar menyebabkan kecurangan laporan keuangan

\subsection{Target Keuangan Menyebabkan Kecurangan Laporan Keuangan}

Target keuangan (financial target) merupakan risiko yang timbul akibat adanya tekanan yang tinggi yang harus dicapai manajemen. Menurut Skousen et al. (2009) ROA menjadi indikator penilaian kinerja manajer. Jika tingkat ROA yang ditetapkan tinggi menyebabkan kecurangan laporan keuangan.

H4. Target Keuangan menyebabkan kecurangan laporan keuangan

\subsection{Sifat Industri Menyebabkan Kecurangan Laporan Keuangan}

Sifat industri (nature of industry) perusahaan yang selalu berdasarkan suatu estimasi, menginginkan keadaan yang baik dalam suatu perusahaan. Penggunaan perkiraan tertentu perusahaan dengan menggunakan estimasi misalnya akun persediaan usang dan akun piutang tak tertagih. Manajer melakukan manipulasi laporan keuangan pada akun-akun tertentu.

H5. Sifat industri menyebabkan kecurangan laporan keuangan 


\subsection{Pengawasan Yang Tidak Efektif Menyebabkan Kecurangan Laporan}

\section{Keuangan}

Kecurangan dapat diminimalkan dengan adanya komite audit dan tingginya efektifitas pengawasan internal. Kecurangan dapat diminimalisir dengan adanya pengawasan yang baik, dalam hal ini komite audit dapat menjadi salah satu alat yang dapat digunakan. Penelitian yang dilakukan oleh Skousen et al. (2009) menghasilkan bahwa anggota komite audit independen yang lebih banyak akan menurunkan tingkat kecurangan laporan keuangan.

H6. Pengawaan yang tidak efektif menyebabkan kecurangan laporan keuangan

\subsection{Rasionalisasi Menyebabkan Kecurangan Laporan Keuangan}

Auditor harus dapat mengidentifikasi kecurangan agar laporan keuangan dapat menghasilkan informasi yang relevan. Frekuensi pergantian auditor biasanya mengindikasikan perusahaan melakukan kecurangan, pergantian auditor dilakukan agar kecurangan laporan keuangan yang dilakukan perusahaan tidak terdeteksi dengan adanya pergantian auditor. Lou dan Wang (2009) menyatakan bahwa kemungkinan terdeteksinya kecurangan laporan keuangan dapat berkurang dengan adanya pergantian auditor, pergantian auditor pada sebuah perusahaan akan mengurangi kemungkinan terdeteksinya kecurangan laporan keuangan oleh pihak auditor.

H7. Pergantian auditor menyebabkan kecurangan laporan keuangan

\section{METODE PENELITIAN}

\subsection{Populasi dan Sampel}

Populasi pada penelitian ini adalah seluruh perusahaan perbankan yang terdaftar di BEI pada tahun 2016 hingga 2019. Perusahaan perbankan yang terdaftar di BEI berjumlah 42 perusahaan yang dinyatakan dalam bentuk Rupiah (Rp). Adapun yang menjadi kriteria dalam pengambilan sampel adalah perusahaan perbankan yang terdaftar di Bursa Efek Indonesia dan tidak delisting pada periode 2016 hingga 2019, serta tidak mengalami kerugian selama periode tersebut. Berdasarkan kriteria sampel, total perusahaan yang memenuhi kriteria sejumlah 37 perusahaan. Jumlah periode pengamatan yang dilakukan dalam penelitian ini selama 4 tahun, maka data yang digunakan dalam penlitian ini sebanyak 148 data penelitian. 


\subsection{Teknik Pengumpulan dan Analisa Data}

Prosedur pengumpulan data dalam penelitian ini menggunakan metode dokumentasi. Pengumpulan data dengan mengakses data-data dari laporan keuangan perusahaan perbankan yang terdaftar di Bursa Efek Indonesia. Metode dilakukan dengan mengumpulkan seluruh data sekunder dari www.idx.co.id. Analisis data dilakukan menggunakan analisis regresi berganda dengan menggunakan SPSS. Sebagai syarat menggunakan regresi terlebih dahulu dilakukan dengan uji asumsi klasik.

\subsection{Operasionalisasi Variabel}

Variabel dependen pada penelitian ini adalah kecurangan laporan keuangan. Variabel kecurangan laporan keuangan diukur dengan menggunakan fraud score model dengan rumus:

\section{FScores $=$ AccrualQuality + FinancialPermormances}

Variabel independen terdiri dari tekanan, peluang dan rasionalisasi.

1. Tekanan diproksikan dengan stabilitas keuangan, target keuangan, kebutuhan keuangan pribadi dan tekanan eksternal. Stabilitas keuangan (financial stability) diproksikan dengan rasio perubahan aset selama 2 tahun. Rasio perubahan aset yang dilambangkan dengan $A C H A N G E$ dapat dihitung dengan rumus:

$$
\text { ACHANGE }=\frac{(\text { Total asset } t-\text { total Asset } t-1)}{\text { Total Asset } t}
$$

Target keuangan (financial target) diukur dengan menggunakan return on asset $(R O A)$, dengan rumus :

$$
R O A=\frac{\text { Earning after interest and tax }}{\text { Total Assets }}
$$

Kebutuhan keuangan pribadi (personal financial need) diproksikan dengan OSHIP. OSHIP dapat dihitung dengan rumus berikut:

$$
\text { OSHIP }=\frac{\text { Total saham yang dimiliki oleh orang dalam }}{\text { Total saham biasa yang beredar }}
$$

Tekanan eksternal (external pressure) pada penelitian ini diukur dengan rasio leverage dengan rumus :

$$
\text { Debt to assets Ratio }=\frac{\text { Total Debt }}{\text { Total Assets }}
$$


2. Peluang/ksesempatan

Kesempatan (opportunities) adalah situasi yang menyebabkan seseorang atau organisasi untuk melakukan kecurangan (fraud). Dalam penelitian ini kesempatan diproksikan dengan nature of industry dan ineffective monitoring.

Sifat industri (nature of industry) diproksikan dengan rasio total piutang dihitung dengan rumus yang digunakan Skousen (2009) yaitu:

$$
\text { RECEIVABLE }=\frac{\text { Receivable }(t)}{\text { sales }(t)}-\frac{\text { Receivable }(t-1)}{\text { sales }(t-1)}
$$

Pengawasan yang tidak efektif (innefective monitoring) diproksikan dengan BDOUT dirumuskan sebagai berikut:

$$
\text { BDOUT }=\frac{\text { Total Independent Boards }}{\text { total Boards }}
$$

3. Rasionalisasi

Rasionalisasi diproksikan dengan perubahan auditor (AUDCHANGE). Apabila terdapat pergantian kantor akuntan publik selama periode 2016 - 2019, diberi kode 1 dan sebaliknya diberi kode 0 .

\section{HASIL DAN PEMBAHASAN}

\subsection{Hasil}

Tabel 1

\begin{tabular}{|c|c|c|c|c|c|c|}
\hline \multirow{2}{*}{\multicolumn{2}{|c|}{ Model }} & \multicolumn{2}{|c|}{$\begin{array}{c}\text { Unstandardized } \\
\text { Coefficients }\end{array}$} & \multirow{3}{*}{$\begin{array}{c}\text { Standardized } \\
\text { Coefficients }\end{array}$} & \multirow{3}{*}{$\frac{\mathrm{T}}{1,460}$} & \multirow{3}{*}{$\begin{array}{l}\text { Sig. } \\
, 148 \\
\end{array}$} \\
\hline & & \multirow{2}{*}{$\begin{array}{l}\mathrm{B} \\
2,373 \\
\end{array}$} & \multirow{2}{*}{$\begin{array}{r}\text { Std. Error } \\
1,626 \\
\end{array}$} & & & \\
\hline 1 & $($ Constant $)$ & & & & & \\
\hline & LG_ACHANGE & $-1,244$ & 2,086 &,- 063 &,- 597 &, 552 \\
\hline & LG_OSHIP & ,055 &, 044 &, 137 & 1,238 & ,219 \\
\hline & LG_LEV & $-1,323$ & 1,498 &,- 090 &,- 883 &, 380 \\
\hline & LG_ROA &,- 368 &, 157 &,- 246 & $-2,343$ &, 022 \\
\hline & LG_BDOUT &,- 855 &, 893 &,- 098 &,- 957 &, 342 \\
\hline & LG_RPT &,- 183 &, 061 &,- 310 & $-2,993$ & ,004 \\
\hline & AUDCHANGE & ,101 & , 148 &, 071 & ,682 & ,497 \\
\hline
\end{tabular}

Hasil Regresi Beganda

Dependent Variable: LG_FSCORE

Sumber: Data diolah 
Persamaan regresi linear berganda sebagai berikut:

FRAUD = 2,373 - 1,244ACHANGE - 1,323LEV + 0,055OSHIP-0,368ROA 0,183RPT - 0,855BDOUT + 0,101AUDCHANGE + $\varepsilon$

Tabel 2

Hasil Uji Koefisien Determinasi

\begin{tabular}{|l|r|r|r|r|}
\hline \multicolumn{7}{|c|}{ Model Summary $^{\mathbf{b}}$} \\
\hline Model & $\mathrm{R}$ & $\mathrm{R}$ Square & $\begin{array}{c}\text { Adjusted R } \\
\text { Square }\end{array}$ & $\begin{array}{l}\text { Std. Error of the } \\
\text { Estimate }\end{array}$ \\
\hline 1 &, $489^{\mathrm{a}}$ &, 239 &, 173 &, 54548 \\
\hline $\begin{array}{l}\text { a. Predictors: (Constant), AUDCHANGE, LG_ACHANGE, LG_ROA, } \\
\text { LG_RPT, LG_BDOUT, LG_LEV, LG_OSHIP } \\
\text { b. Dependent Variable: LG_FSCORE }\end{array}$ \\
\hline
\end{tabular}

Sumber : Data diolah

Nilai koefisien adjusted R2 adalah sebesar 0,173. Nilai tersebut mengindikasikan bahwa variabel independen mampu menjelaskan variabel dependen sebesar $17,3 \%$ dan sisanya sebesar $82,7 \%$ dijelaskan oleh faktor-faktor lain yang tidak diteliti dalam penelitian ini

Tabel 3

\section{Uji Signifikansi Parsial (Uji T)}

\section{Coefficients $^{\mathrm{a}}$}

\begin{tabular}{|c|c|c|c|c|c|c|}
\hline \multirow{2}{*}{\multicolumn{2}{|c|}{ Model }} & \multicolumn{2}{|c|}{$\begin{array}{c}\text { Unstandardized } \\
\text { Coefficients }\end{array}$} & \multirow{2}{*}{$\frac{\begin{array}{c}\text { Standardized } \\
\text { Coefficients }\end{array}}{\text { Beta }}$} & \multirow[b]{2}{*}{$\mathrm{T}$} & \multirow[b]{2}{*}{ Sig. } \\
\hline & & B & Std. Error & & & \\
\hline \multirow[t]{8}{*}{1} & \multirow{8}{*}{$\begin{array}{l}\text { (Constant) } \\
\text { LG_ACHANG } \\
\text { E } \\
\text { LG_OSHIP } \\
\text { LG_LEV } \\
\text { LG_ROA } \\
\text { LG_BDOUT } \\
\text { LG_RPT } \\
\text { AUDCHANGE }\end{array}$} & 2,373 & 1,626 & & 1,460 & , 148 \\
\hline & & $-1,244$ & 2,086 &,- 063 &,- 597 &, 552 \\
\hline & & ,055 &, 044 & ,137 & 1,238 & ,219 \\
\hline & & $-1,323$ & 1,498 &,- 090 &,- 883 & ,380 \\
\hline & &,- 368 & , 157 &,- 246 & $-2,343$ & ,022 \\
\hline & &,- 855 & ,893 &,- 098 &,- 957 & ,342 \\
\hline & &,- 183 & ,061 &,- 310 & $-2,993$ & ,004 \\
\hline & & ,101 & 148 & 071 & 682 & ,497 \\
\hline
\end{tabular}

a. Dependent Variable: LG_FSCORE

Sumber:Data diolah 


\subsection{Pembahasan}

Tingkat perubahan aset (ACHANGE) tidak berpengaruh terhadap kecurangan laporan keuangan secara parsial karena diperoleh hasil $\mathrm{T}_{\text {hitung }}<\mathrm{T}_{\text {tabel }}(0,597<1,199006)$ dengan signifikansi 0,552. nilai signifikansi perubahan aset lebih besar dari signifikansi yang telah ditetapkan $(0,552>0,05)$. Hasil penelitian ini sejalan dengan penelitian Utomo (2018) dan Nugroho (2017) dimana perubahan aset tidak menyebabkan kecurangan laporan keuangan..

Variabel kebutuhan keuangan pribadi (personal financial need) yang diproksikan dengan tingkat kepemilikan saham orang dalam (OSHIP) tidak berpengaruh terhadap kecurangan laporan keuangan secara parsial karena nilai signifikansi tingkat perubahan aset lebih besar dari signifikansi yang telah ditetapkan $(0,219>0,05)$. Penelitian ini sejalan dengan penelitian (Tiffiani \& Marfuah, 2015) dan penelitian (Nugroho, 2017).

Variabel tekanan eksternal (external pressure) yang diproksikan dengan tingkat Leverage (LEV) tidak berpengaruh terhadap kecurangan laporan keuangan secara parsial karena diperoleh nilai signifikansi tingkat leverage lebih besar dari tingkat signifikansi yang telah ditetapkan $(0,380>0,05)$. Penelitian ini selaras dengan Subroto (2012) yang menyatakan bahwa kemampuan perusahaan dalam memenuhi kewajibannya (LEV) tidak berpengaruh terhadap kecurangan pelaporan keuangan.

Variabel target keuangan (financial target) yang diproksikan dengan tingkat Return on Assets (ROA) berpengaruh terhadap kecurangan laporan keuangan secara parsial. Hal ini dapat dilihat dari hasil $\mathrm{T}_{\text {hitung }}>\mathrm{T}_{\text {tabel }}(2,343>1,199006)$ dan nilai signifikansi Return on Asset lebih kecil dari tingkat signifikansi yang telah ditetapkan $(0,022<0,05)$.

Variabel sifat industi (nature of industry) yang diproksikan dengan tingkat Transaksi Pihak Istimewa (RPT) berpengaruh terhadap kecurangan laporan keuangan secara parsial karena diperoleh hasil $\mathrm{T}_{\text {hitung }}>\mathrm{T}_{\text {tabel }}(2,993>1,199006)$ dan nilai signifikansi lebih kecil dari tingkat signifikansi yang telah ditetapkan $(0,004<0,05)$. Keterlibatan manajemen dalam pengambilan keputusan menyebabkan adanya traansaksi istimewa yang kompleks dan risiko inheren. Manipulasi yang dilakukan oleh manajemen akan dapat dengan mudah dilakukan karena adanya transaksi dengan pihak istimewa yang menimbulkan risiko salah saji material. Kecurangan yang dilakukan 
manajemen semakin mudah dilakukan dengan adanya transaksi dengan pihaknistimewa yang rumit yang menimbulkan risiko salah saji material. ( Lou dan Wang, 2009).

Variabel pengawasan yang tidak efektif (inneffective monitoring) yang diproksikan dengan anggota independent audit (BDOUT) tidak berpengaruh terhadap kecurangan laporan keuangan secara parsial, hal ini dapat dilihat dari nilai signifikansi sebesar $0,342>0,05)$. Hal tersebut berarti bahwa berapapun jumlah dewan komisaris independen dalam susunan dewan komisaris tidak mempengaruhi praktik kecurangan laporan keuangan yang dilakukan oleh manajemen perusahaan.

Variabel rasionalisasi (rationalization) yang diproksikan dengan perubahan kantor akuntan publik ( $A U D C H A N G E$ ) tidak berpengaruh terhadap kecurangan laporan keuangan secara parsial. Hal ini dapat dilihat dari nilai signifikansi sebesar 0,497>0,05. Hal ini menunjukkan bahwa ada tidaknya pergantian auditor dalam perusahaan perbankan tidak akan mempengaruhi terjadinya financial statement fraud dalam perusahaan perbankan. Hasil penelitian ini sejalan dengan penelitian yang dilakukan Kartika et. al. (2017) dan Tiffani dan Marfuah (2015).

\section{KESIMPULAN}

Stabilitas keuangan, kebutuhan keuangan pribadi, tekanan eksternal, pengawasan yang tidak efektif dan rasionalisasi tidak menyebabkan kecurangan laporan keuangan, sedangkan target keuangan dan sifat industri menyebabkan kecurangan laporan keuangan.

\section{DAFTAR PUSTAKA}

AICPA, SAS No. 99. (2002). Consideration of Fraud in a Financial Statement Audit. New York.

Amaliah Bese Nur, dkk. 2015. Perspektif Fraud Diamond Theory Dalam Menjelaskan Earnings Management Non-Gaap Pada Perusahaan Terpublikasi Di Indonesia. Jurnal Akuntansi dan Auditing Indonesia (JAAI) Volume 19 No.1 Hal. 51-67.

Bursa Efek Indonesia. (diakses pada 20 April 2020, 16.30 WIB) Avialable: www.idx.co.id

Dechow, P. (1994). Accounting Earnings and Cash Flows as Measures of Firm Performance. The Role of Accounting Accrual. Journal of Accounting and Economics 17. 3 - 42. 
DetikNews.Com. (Diakses 10 maret 2020, 12.59 WIB). "Korupsi Rp. 13 M, Pegawai Bank Di Bekasi ditahan Kejati Jabar". Bandung: Dony Indra Ramadhan. Available : www.detiknews.com.

Kartika, Nella. Nugraheni dan Hanung Triatmoko. 2017. Analisis Faktor-Faktor Yang Mempengaruhi Terjadinya Financial Statement Fraud: Perspektif Diamond Fraud Theory. Jurnal Akuntansi dan Auditing Vol. 14 No. 2 Hal.118-143.

KlikAnggaran.com. (diakses 10 maret 2020, 12:58 WIB). "DPR Temukan Pemolesan Laporan Keuangan Bank BTN tahun 2018". Jakarta: M.J. Putra. Available : https://www.klikanggaran.com.

Lou, Y., \& Wang, M. (2009). Fraud Risk Factor Of The Fraud Triangle Assessing The Likelihood Of Fraudulent Financial Reporting. Journal of Business \& Economics Research (JBER), 7(2).

Nugroho, H. (2017). Analisis Financial Statement Fraud Dalam Perspektif Triangle Fraud Pada Perbankan Yang Terdaftar Di Bursa Efek Indonesia Periode 20102014. GEMA. Volume IX, Nomor 1.

Ratmono, Dwi dkk. 2017. Dapatkah Teori Fraud Triangle Menjelaskan Kecurangan Dalam Laporan Keuangan?. Jurnal Akuntansi dan Auditing Vol.14 No. 2. Hal. 100-117

SAS No. 99. (2002). Consideration of Fraud in a Financial Statement Audit. New York.

Skousen, C. J., \& Twedt, B. (2009). Fraud in Emerging Markets: A Cross Country Analysis.

Skousen, C., Smith, K., \& Wright , C. (2008). Detecting and Predecting Financial Statement Fraud: The Effectiveness of The Fraud Triangle and SAS 99.

Tiffani, L., \& Marfuah. (2015). Deteksi Financial Statement Fraud Dengan Analisis Fraud Triangle Pada Perusahaan Manufaktur yang terdaftar di Bursa Efek Indonesia. Jurnal Akuntansi \& Auditing Indonesia (JAAI). Vol 19, No. 2.

Yesiariani, Merissa dan Rahayu, Isti. 2017. Deteksi financial statement fraud: Pengujian dengan fraud diamond. Jurnal Akuntansi \& Auditing Indonesia, Vol. 21 No. 1 Hal. 49-60. 